Check for updates

Cite this: Nanoscale Adv., 2019, 1, 2873

\title{
Low-temperature activation of carbon black by selective photocatalytic oxidation $\dagger$
}

\author{
Niels R. Ostyn, (D) a Julian A. Steele, (D) a Michiel De Prins, (D) ${ }^{a}$ \\ Sreeprasanth Pulinthanathu Sree, (DD a C. Vinod Chandran, (D) a Wauter Wangermez, ${ }^{a}$ \\ Gina Vanbutsele, ${ }^{a}$ Jin Won Seo, (D) ${ }^{b}$ Maarten B. J. Roeffaers, (D) ${ }^{a}$ Eric Breynaert (D) ${ }^{a}$ \\ and Johan A. Martens (iD)*a
}

Carbon black is chemically modified by selective photocatalytic oxidation, removing amorphous carbon and functionalizing the graphitic fraction to produce porous, graphitized carbon black, commonly used as an adsorbent in chromatography. In contrast to pyrolytic treatments, this photocatalytic modification proceeds under mild reaction conditions using oxygen, nitric oxide, water vapor and a titanium dioxide photocatalyst at $150{ }^{\circ} \mathrm{C}$. The photo-oxidation can be performed both with the photocatalyst in close proximity (contact mode) or physically separated from the carbon. Structural analysis of remotely photooxidized carbon black reveals increased hydrophilic properties as compared to pyrolysis at $700{ }^{\circ} \mathrm{C}$ in a $\mathrm{N}_{2}$ atmosphere. Carbon black photo-oxidation selectively mineralizes $\mathrm{sp}^{3}$-hybridized carbon, leading to enhanced graphitization. This results in an overall improved structural ordering by enriching carbon black with $\mathrm{sp}^{2}$-hybridized graphitic carbon showing decreased interplanar distance, accompanied by a twofold increase in the specific surface area. In addition, the photo-oxidized material is activated by the presence of oxygen functionalities on the graphitic carbon fraction, further enhancing the adsorptive properties.

Received 27th March 2019

Accepted 21st May 2019

DOI: $10.1039 / c 9 n a 00188 c$

rsc.li/nanoscale-advances

\section{Introduction}

Carbon black (CB) represents a family of carbon powders produced on a large scale (over 12 million tons per year). ${ }^{1}$ Its structural properties, particle size and porosity, strongly depend on the primary feedstock and manufacturing process (thermal decomposition). Feedstocks primarily include oil, coal or natural gas. Next to its main application as a black pigment and electrical conductor, CB serves as an excellent reinforcing filler in tires and other rubber products because of its mechanical, chemical and electrical properties. ${ }^{1,2} \mathrm{CB}$ is generally described as large agglomerates of graphitic and amorphous carbon aggregates consisting of spherical primary particles (Fig. 1). A distinguishing property is the carbon atom hybridization, where $\mathrm{sp}^{2}$-hybridization is characteristic of the graphite fraction, while $\mathrm{sp}^{3}$-hybridized carbon typically reflects the

${ }^{a}$ Centre for Surface Chemistry and Catalysis, $K U$ Leuven, Celestijnenlaan 200F, box 2461, 3001 Heverlee, Belgium. E-mail: johan.martens@kuleuven.be; Tel: +32 1632 1637

${ }^{b}$ Department of Materials Engineering, KU Leuven, Kasteelpark Arenberg 44, 3001 Heverlee, Belgium

$\dagger$ Electronic supplementary information (ESI) available: Temperature profile during photoreaction; gas specifications; example of deconvoluted Raman spectrum; wide Raman spectra of $\mathrm{CB}, \mathrm{CB}_{\mathrm{C} 72}$ and $\mathrm{CB}_{\mathrm{C} 165}$ with bands in high-wavenumber range; Harkins-Jura $t$-plots of $\mathrm{CB}$ and $\mathrm{CB}_{\mathrm{R} 72}$. See DOI: 10.1039/c9na00188c amorphous hydrocarbon fraction. ${ }^{3} \mathrm{CB}$ particles, with sizes ranging from 10 to $100 \mathrm{~nm},{ }^{3-5}$ consist of a rather amorphous core and quasi-crystalline shell with graphitic carbon stacks. ${ }^{5-7}$ The carbon particles are often described as onion-like structures held together by van der Waals forces. ${ }^{8}$ These graphitic nanocrystallites typically exhibit turbostraticity, i.e. large structural disorder as a result of rotational misalignment. The coexistence of a disordered carbon fraction alongside ordered carbon led to the classification of $\mathrm{CB}$ as an intermediate between amorphous and crystalline carbon materials. ${ }^{3,5}$

Many applications require modification of pristine carbon black. Graphitized carbon black (GCB) is, for example, a widely used adsorbent offering large external surface area with excellent homogeneity and purity. This adsorbent is mainly suitable for selective purification processes in chromatography. ${ }^{9-11}$

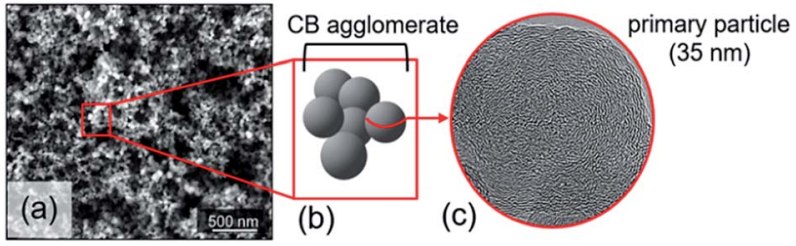

Fig. 1 (a) High-resolution SEM image of CB nanoparticles. (b) Simplified representation of CB morphology. (c) High-resolution TEM micrograph of $\mathrm{CB}$ nanoparticle. 
Unfortunately, the production of GCB by thermal treatment of $\mathrm{CB}$ in anoxic conditions is energy intensive due to the required high temperatures. ${ }^{\mathbf{1 2 - 1 4}}$ This has motivated research to increase the energy efficiency, for example, by catalytic or pressure induced graphitization. Though more sustainable, these processes still require fairly high temperatures $\left(600-2500{ }^{\circ} \mathrm{C}\right)$ or pressures (0.5-5 GPa). ${ }^{15-18}$

In this work, low-temperature photocatalytic oxidation is presented for chemical modification of CB. This ultraviolet (UV) light driven process is compared to a classical thermal treatment of CB. Titanium dioxide $\left(\mathrm{TiO}_{2}\right)$ materials are specifically known for their excellent photocatalytic activity in the decomposition of organic compounds. ${ }^{19,20}$ For automotive applications, $\mathrm{TiO}_{2}$-based photocatalysis has been studied for complete oxidation of $\mathrm{CB}$ into carbon dioxide at temperatures as low as $150{ }^{\circ} \mathrm{C}^{21,22}$ While photo-oxidation is too slow for practical application in diesel particulate filter regeneration, $\mathrm{TiO}_{2}$ photocatalysis could be of interest for CB activation. Surface oxidation of CB, for example by acidic and electrochemical treatment, renders it as an active catalyst for the water and alcohol oxidation reactions. ${ }^{23}$ Many studies on photocatalytic mineralization of carbon materials by UVilluminated $\mathrm{TiO}_{2}$ show the involvement of airborne oxidant species. These gas phase oxidants, photogenerated by $\mathrm{TiO}_{2}$, allow a remote oxidation at distances over $2 \mathrm{~mm} .{ }^{24-30}$ Structural carbon modifications underpinning the photocatalytic oxidation were revealed using a combination of nuclear magnetic resonance (NMR) and Raman spectroscopies, X-ray diffraction (XRD) and transmission electron microscopy (TEM). The carbon black morphology and porosity have been investigated using scanning electron microscopy (SEM) and nitrogen physisorption. Energy dispersive X-ray spectroscopy (EDS) and electron energy loss spectroscopy (EELS) were particularly useful for revealing the structural and elemental composition.

\section{Experimental section}

\subsection{Materials}

Printex U carbon black (Degussa, now Orion Engineered Carbons) is a synthetic carbon produced from natural gas. ${ }^{31}$ It has a primary particle size of around $30 \mathrm{~nm}$, specific surface area ranging from 100 to $141 \mathrm{~m}^{2} \mathrm{~g}^{-1}$ and a volatile organic compound fraction of 5 to $6 \mathrm{wt} \%$. The carbon and oxygen contents are about 90 and 8 wt $\%$, respectively. ${ }^{21,31-33}$ CristalACTIV ${ }^{\mathrm{TM}}$ PC-500 $\mathrm{TiO}_{2}$ (Cristal), an almost pure anatase phase ( $\geq 99.0 \mathrm{wt} \%$ ), was used as the photocatalyst. This $\mathrm{TiO}_{2}$ material has a specific surface area of approximately $350 \mathrm{~m}^{2} \mathrm{~g}^{-1}$ and a primary particle size of about $10 \mathrm{~nm}$. CB and $\mathrm{TiO}_{2}$ were slurried by magnetic stirring in isopropanol (Fisher Scientific) at $400 \mathrm{rpm}$ for 15 minutes, at concentrations of 0.71 and $7.1 \mathrm{~g}$ $\mathrm{L}^{-1}$ respectively.

\subsection{Photocatalytic oxidation}

Photocatalysis experiments were carried out using a custommade, heated, flat rectangular photoreactor with internal volume of $82 \mathrm{~cm}^{3}$, sealed at atmospheric pressure by a borosilicate glass cover plate. Constant temperature during photoreaction is obtained by the stainless steel thermostatic support with temperature control (Fig. S1 $\dagger$ ). The flat photoreactor was illuminated from the top by UV light with a wavelength of $368 \mathrm{~nm}$ (Plus Lamp ${ }^{\mathrm{TM}}, 15 \mathrm{~W}$ ). Gases (alpha gas 1: $\mathrm{O}_{2}$ and NO, $\mathrm{N}_{2}$ and $\mathrm{H}_{2}$ (for leakage test)) were fed into the photoreactor through Teflon ${ }^{\mathrm{TM}}$ tubes using mass flow controllers (Bronkhorst) (see Table $\mathrm{S} 1 \uparrow$ for specifications). Water vapor was added to the gas flow by a thermostatic saturator. The reactor outlet gases were diluted with $\mathrm{N}_{2}$ carrier gas and transferred on-line to autocalibrated gas analyzers (ABB) for $\mathrm{NH}_{3}, \mathrm{NO}$ and $\mathrm{NO}_{2}$ (UV detector), and $\mathrm{CO}, \mathrm{CO}_{2}$ and $\mathrm{N}_{2} \mathrm{O}$ (NDIR detector), ensuring quantitative analysis.

The configuration of the $\mathrm{TiO}_{2}$ and CB layers in the photoreactor is presented in Fig. 2. Two different modes of operation were used, either with $\mathrm{TiO}_{2}$ in close proximity of carbon black (Fig. 2a), referred to as contact mode, or with $\mathrm{TiO}_{2}$ physically separated from the carbon layer (Fig. 2b), denoted as remote mode.

For contact mode photo-oxidation, $430 \mu \mathrm{L}$ of the $\mathrm{TiO}_{2}$ and CB suspensions were pipetted layer-by-layer on a glass support, with an intermediate drying step at room temperature. CB was pipetted on top of the dried $\mathrm{TiO}_{2}$ with a $\mathrm{CB}: \mathrm{TiO}_{2}$ weight ratio of $1: 10$. Supported films were further dried in an oven at $150{ }^{\circ} \mathrm{C}$ for at least $1 \mathrm{~h}$. In contact mode, UV front irradiation was used, allowing suitable access for Raman scattering, SEM, TEM-EELS and EDS experiments of the treated CB. Contact photo-oxidation was not analyzed by NMR spectroscopy, XRD and nitrogen physisorption due to the carbon- $\mathrm{TiO}_{2}$ mix. For remote photo-oxidation, $\mathrm{TiO}_{2}$ and CB layers were deposited on different glass supports, separated by $25 \mu \mathrm{m}$-thick strips of polyimide to space the reaction (Kapton ${ }^{\circledR} \mathrm{HN}$ ). The $\mathrm{CB}: \mathrm{TiO}_{2}$ weight ratio was $1: 5$ in remote experiments, that were performed with back UV irradiation to prevent absorption of light by CB.

Photo-oxidation experiments were initiated by purging the tubes and loaded photoreactor with dry nitrogen for about 15

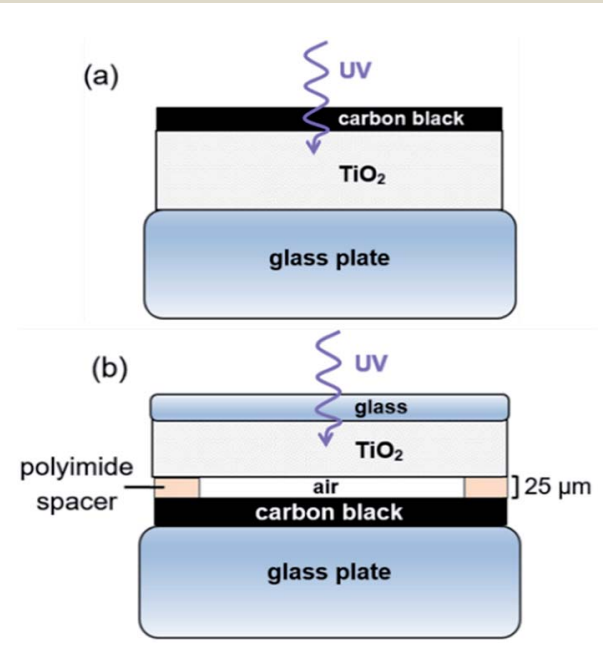

Fig. 2 Configuration of $\mathrm{CB}$ and $\mathrm{TiO}_{2}$ layers. (a) Contact photocatalysis. (b) Remote photocatalysis experiments. 
minutes while heating to $150{ }^{\circ} \mathrm{C}$. A continuous gas flow composed of $21 \mathrm{vol} \% \mathrm{O}_{2}, 5000 \mathrm{ppm} \mathrm{NO}$ and $1.8 \mathrm{vol} \% \mathrm{H}_{2} \mathrm{O}$, referred to as gas mixture 1 , was subsequently sent through the photoreactor in the dark at a rate of $5.4 \mathrm{~L} \mathrm{~h}^{-1}$. Batch experiments were performed by closing the photoreactor inlet and outlet valves after stabilization of the gas concentrations in gas mixture 1 , followed by switching on the UV lamp. Eventually, the product gas mixture was analyzed by sending it to the analyzers using nitrogen carrier gas. $\mathrm{NO}_{x}$ conversion and $\mathrm{N}_{2} \mathrm{O}$ formation were calculated by the nitrogen atom balance.

\subsection{Carbon black pyrolysis}

Carbon black was thermally treated at $700{ }^{\circ} \mathrm{C}$ in an inert $\mathrm{N}_{2}$ atmosphere. The sample was heated at a rate of $1{ }^{\circ} \mathrm{C} \mathrm{min}{ }^{-1}$ until the set temperature was reached. This maximum pyrolysis temperature was maintained for $5 \mathrm{~h}$, after which CB was cooled down to room temperature.

\subsection{Carbon black characterization}

NMR experiments were carried out on a Bruker AVIII 500 spectrometer with ${ }^{1} \mathrm{H}$ Larmor frequency at $500.13 \mathrm{MHz}$, operating at a static magnetic field of $11.74 \mathrm{~T}$. Samples possessing the same sample weights were loaded in $1.9 \mathrm{~mm}$ zirconia rotors with vespel caps and with bottom and top columns of zirconia powder. Direct excitation ${ }^{1} \mathrm{H}$ MAS NMR measurements were recorded at a MAS frequency of $40 \mathrm{kHz}$, using $\pi / 2$ pulses of 200 $\mathrm{kHz}$ and recycle delays of $10 \mathrm{~s}$ (32 scans). Spectra were chemical shift calibrated versus TMS, using adamantane as a secondary reference.

Raman scattering experiments were performed on a homemade system using a TriVista ${ }^{\mathrm{TM}}$ Spectrometer System with CCD detector from Princeton Instruments. Laser excitation was achieved using the $488 \mathrm{~nm}(2.54 \mathrm{eV})$ emission of an $\mathrm{Ar}^{+}$laser, coupled into an optical microscope (IX 71) equipped with an $\times 20$ magnification objective. A laser wavelength of $488 \mathrm{~nm}$ was selected to resonantly enhance Raman signals in the carbon materials, with laser powers kept relatively low $(<6 \mathrm{~mW})$ to exclude excessive sample heating. All Raman spectra were recorded within the range $600-3100 \mathrm{~cm}^{-1}$ and further analyzed using the Multipeak Fitting 2 package in the Igor Pro software program. An example of a deconvoluted spectrum is provided in the ESI (Fig. S2†).

XRD was performed using a STOE Powder Diffraction System (STOE) with $\mathrm{Cu} \mathrm{K} \alpha$ radiation (1.54060 $\AA$ ) in the $2 \theta$ range $0-90^{\circ}$. Samples were loaded in small capillary tubes. The diffraction patterns were analyzed with the STOE WinXPOW powder diffraction software.

High-Resolution (HR) SEM was carried out on a Nova NanoSEM 450 scanning electron microscope (FEI, Eindhoven). The carbon sample deposited on a small Al plate (before and after photo-oxidation) was attached to an Al stub with carbon tape, followed by imaging without any further sample modification. For the HR TEM measurement, the carbon samples were prepared by placing a droplet of the colloidal dispersion in isopropanol on a carbon-coated copper grid. TEM micrographs were taken using an ARM200F transmission electron microscope (JEOL) operating at $200 \mathrm{kV}$ equipped with a cold field emission gun, energy dispersive X-ray detector and Gatan Image Filter (GIF, Tridiem 863 Gatan).

Nitrogen physisorption was performed using a TriStar Surface Area and Porosity Analyzer from Micromeritics. The CB samples were pretreated by heating the powders to $400{ }^{\circ} \mathrm{C}$ under $\mathrm{N}_{2}$ atmosphere using the SmartPrep ${ }^{\mathrm{TM}}$ Programmable Degas System from Micromeritics. BET surface areas and BJH cumulative pore volumes were obtained by TriStar 3000 software calculations. The micropore volumes were obtained by $t$-plot analysis.

\section{Results and discussion}

CB photo-oxidation at $150{ }^{\circ} \mathrm{C}$ using anatase $\mathrm{TiO}_{2}$ in presence of $\mathrm{O}_{2}, \mathrm{NO}_{x}$ and $\mathrm{H}_{2} \mathrm{O}$ produces carbon oxides $\left(\mathrm{CO}_{x}\right)$, while reducing both $\mathrm{NO}$ and $\mathrm{NO}_{2}$ into chemically inert $\mathrm{N}_{2}$. Table 1 shows $\mathrm{CO}_{2}$ and $\mathrm{CO}$ production, $\mathrm{NO}_{x}$ conversion and $\mathrm{N}_{2} \mathrm{O}$ byproduct formation, during two consecutive photocatalytic runs, starting from $5 \mathrm{mg}$ of $\mathrm{CB}\left(\mathrm{CB}: \mathrm{TiO}_{2}\right.$ weight ratio of $1: 10)$. In between the two runs, the headspace of the photoreactor was renewed by gas mixture $1\left(21 \% \mathrm{O}_{2}, 5000 \mathrm{ppm}\right.$ NO and $1.8 \% \mathrm{H}_{2} \mathrm{O}$ ). Overall, $30.2 \%$ of the initial $\mathrm{CB}$ converted into $\mathrm{CO}_{2}(97.7 \%)$ and $\mathrm{CO}(2.3 \%)$. Gas analysis after the second photocatalytic run shows a lower carbon oxidation rate compared to the initial run. This decrease indicates more reactive $\mathrm{CB}$ was present at the photo-oxidation onset, as also confirmed by higher $\mathrm{NO}_{x}$ conversion in the first photocatalytic run. Next to a less easy oxidation of amorphous carbon to gaseous $\mathrm{CO}_{x}$, the decreased $\mathrm{CO}_{2}$ formation in the second run could also be ascribed to an increased formation of stable oxygen functionalities on CB surface. Due to their CB oxidation performance, $\mathrm{NO}_{x}$ species are largely reduced into $\mathrm{N}_{2}$, but a small amount of $\mathrm{N}_{2} \mathrm{O}$ forms as a photoreaction byproduct (see Table 1). In a $72 \mathrm{~h}$ control experiment at $150{ }^{\circ} \mathrm{C}$ in gas mixture 1, involving neither $\mathrm{TiO}_{2}$ nor UV light, $10.0 \%$ of $\mathrm{CB}$ converted into $\mathrm{CO}_{2}(80.1 \%)$ and $\mathrm{CO}(19.9 \%)$. In addition, the $\mathrm{NO}_{x}$ conversion only reached $71.0 \%$, emphasizing the essential contribution of anatase $\mathrm{TiO}_{2}$. A second $72 \mathrm{~h}$ control experiment at $150{ }^{\circ} \mathrm{C}$ without $\mathrm{TiO}_{2}$ was performed in inert $\mathrm{N}_{2}$ under UV light to show the effect of only heat and light. This experiment converted only $2.8 \%$ of $\mathrm{CB}$ into $\mathrm{CO}_{2}(89.1 \%)$ and CO $(10.9 \%)$.

Chemical modification of $\mathrm{CB}$ by photo-oxidation can be characterized using ${ }^{1} \mathrm{H}$ NMR spectroscopy, especially by comparing remotely photo-oxidized $\mathrm{CB}\left(\mathrm{CB}_{\mathrm{R} 72}\right)$ with thermally treated $\left(\mathrm{CB}_{700}\right)$ and pristine $\mathrm{CB}(\mathrm{CB}) .{ }^{1} \mathrm{H}$ MAS NMR spectra for these samples, recorded at $40 \mathrm{kHz}$ using a $1.9 \mathrm{~mm}$ triple channel MAS probe, are shown in Fig. 3, before and after drying in vacuum at $150{ }^{\circ} \mathrm{C}$. For these measurements, $1.9 \mathrm{~mm}$ zirconia rotors equipped with vespel top and bottom caps were used, packing small columns of zirconia powder at the bottom and top of the rotor to center the carbon samples and avoid contamination of the rotor caps.

In the spectra in Fig. 3, the area highlighted in blue is the rotor background. The region highlighted with green 
Table 1 Formation of $\mathrm{CO}_{x}$ and $\mathrm{N}_{2} \mathrm{O}$ byproduct and conversion of $\mathrm{NO}_{x}$ during contact mode photo-oxidation

\begin{tabular}{lclll}
\hline UV illumination period & $\begin{array}{l}\mathrm{CO}_{2} \text { formed } \\
{[\%]}\end{array}$ & $\begin{array}{l}\mathrm{CO} \text { formed } \\
{[\%]}\end{array}$ & $\begin{array}{l}\mathrm{NO}_{x} \text { conversion } \\
{[\%]}\end{array}$ \\
\hline $0-72 \mathrm{~h}(72 \mathrm{~h})$ & 20.4 & 0.4 & 95.2 & $\begin{array}{l}\mathrm{N}_{2} \mathrm{O} \\
\text { formed [\%] }\end{array}$ \\
$72-165 \mathrm{~h}(93 \mathrm{~h})$ & 9.1 & 0.3 & 90.6 & 12.7 \\
Total & 29.5 & 0.7 & 92.9 & 10.7 \\
\end{tabular}

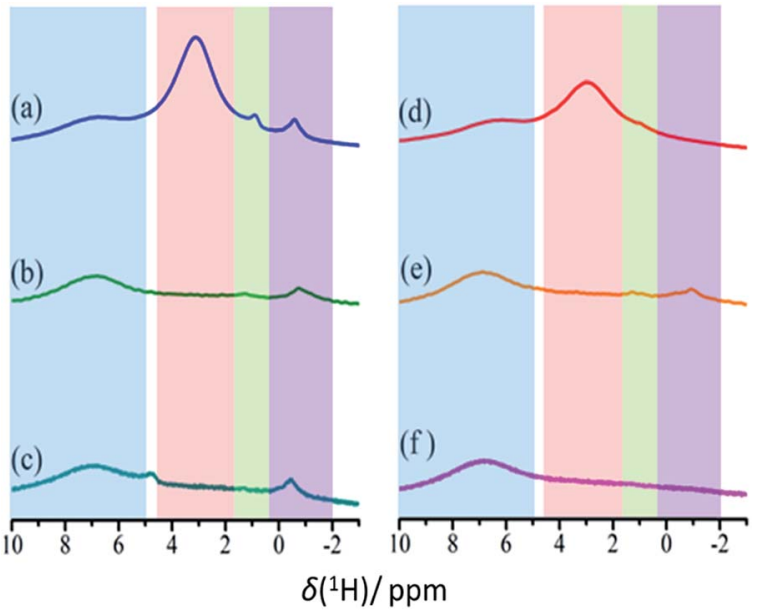

Fig. 3 Magic angle spinning ${ }^{1} \mathrm{H}$ NMR of (a) $\mathrm{CB}_{\mathrm{R} 72}$, (b) $\mathrm{CB}_{700}$ and (c) pristine $C B$, and their respective dried versions (d), (e) and ( $f$ ) at a spinning frequency of $40 \mathrm{kHz}$ and at a static magnetic field of $11.74 \mathrm{~T}$.

represents water associated with zirconia powder, as has been confirmed with a rotor packed with zirconia powder only. All other resonances result from the presence of water in different environments. The region highlighted in red is assigned to the water clusters associated with the oxidized carbon. This signal is exclusively present in the photocatalytically oxidized sample $\mathrm{CB}_{\mathrm{R} 72}$ under both humid and dry conditions. The region with purple color is attributed to water trapped between with crystalline carbon fractions, similar to the case of diamagnetic shifts of water resonances in literature. ${ }^{34,35}$ Fig. 4 illustrates different types of water contained in $\mathrm{CB}_{\mathrm{R} 72}$, as derived from the ${ }^{1} \mathrm{H}$ NMR analysis. The higher water affinity of the photo-oxidized sample as compared to the pristine and thermally treated CB samples could be related to surface functionalization, but also to increased porosity in the sample. This high affinity is evident from the spectra of CB samples in humid and dry conditions. Upon drying however, complete removal of this water fraction was only observed for $\mathrm{CB}$ and $\mathrm{CB}_{700}$, while only partial removal was observed for $\mathrm{CB}_{\mathrm{R} 72}$. In the spectrum of humid $\mathrm{CB}$, also a resonance around $4.7 \mathrm{ppm}$ is observed, representing bulk water. Summarizing, ${ }^{1} \mathrm{H}$ NMR points towards the photocatalytic formation of $\mathrm{CB}$ with oxidized graphitic fraction showing high water affinity.

Raman spectra of pristine $\mathrm{CB}$ and $\mathrm{CB}$ photo-oxidized in contact and remote modes $\left(\mathrm{CB}, \mathrm{CB}_{\mathrm{c} 165}, \mathrm{CB}_{\mathrm{C} 72}\right.$, and $\mathrm{CB}_{\mathrm{R} 72}$ respectively) are shown in Fig. 5. Analyzing the Raman spectra in detail, multiple bands can be observed. The $\mathrm{D}$ band, at
$1360 \mathrm{~cm}^{-1}$, is often denoted as the disorder band because it indicates the presence of defects in an $\mathrm{sp}^{2}$-hybridized carbon structure. The $\mathrm{D}$ band represents a breathing mode of sixmembered carbon rings with $\mathrm{A}_{1 \mathrm{~g}}$ symmetry, corresponding to out-of-plane displacements, a process exclusively activated by defects. The $\mathrm{G}$ band, at $1600 \mathrm{~cm}^{-1}$, is referred to as the graphite band and represents planar $\mathrm{sp}^{2}$ carbon. It is ascribed to in-plane bond stretching vibrations of pairs of $\mathrm{sp}^{2}$-hybridized carbon atoms with $\mathrm{E}_{2 \mathrm{~g}}$ symmetry. ${ }^{36-38}$ The intensity ratio of the $\mathrm{D}$ and $\mathrm{G}$ bands $\left(I_{\mathrm{D}} / I_{\mathrm{G}}\right)$ is therefore a suitable probe of the degree of disorder in the system.

Upon contact mode and remote photo-oxidation, the Raman spectra show a similar spectral evolution for both samples. Comparing the spectra (Fig. 5), a more ordered quasi-crystalline CB structure can be observed, due to selective removal of amorphous carbon. This results in better resolved D and G bands by the gradual removal of the amorphous carbon band overlapping at $1530 \mathrm{~cm}^{-1} \cdot \cdot^{-5,18,39,40}$ Overall, partial graphitization can be observed from the upward shift of both D and $G$ bands, the decrease in D band width, the more symmetric $\mathrm{G}$ band and the overall $I_{\mathrm{D}} / I_{\mathrm{G}}$ decrease. Higher $\mathrm{D}$ and $\mathrm{G}$ band frequencies and lower FWHMs are attributed to a higher degree of order in the CBs. ${ }^{\mathbf{4 1 , 4 2}}$ Mean Raman parameters for the D and G bands allow quantifying the difference between the materials (Table 2). While the extent of spectral modification is lower for $\mathrm{CB}_{\mathrm{R} 72}$, as a result of the lower photo-oxidation rate at extended distances and the lower $\mathrm{CB}: \mathrm{TiO}_{2}$ weight ratio $(1: 5)$ as compared to contact photocatalysis, both samples exhibit a tendency towards graphitization.

Graphitization leads to a less asymmetric $\mathrm{G}$ band, as indicated by the reduced magnitude of the ExpTau values in Table 2 . ExpTau describes the exponential decay of the exponentially modified Gaussian functions, so the larger the magnitude, the faster the decay and the more asymmetric the $\mathrm{G}$ band shape. After an extended photo-oxidation time, the graphitic CB fraction gradually becomes oxidized as can be seen from the continuous decrease in $\mathrm{G}$ band full width at half maximum (FWHM) and the $I_{\mathrm{D}} / I_{\mathrm{G}}$ increase from 2.4 to 2.7 for $\mathrm{CB}_{\mathrm{C} 165}$. The gas analysis results (supra), on the one hand, indicate the partial graphitization occurs by conversion into $\mathrm{CO}_{2}$ and $\mathrm{CO}$ through the strong oxidative effect of ${ }^{\circ} \mathrm{O}_{2}{ }^{-}, \mathrm{NO}_{x}$ radicals and ${ }^{\circ} \mathrm{OH}$. An electron paramagnetic resonance (EPR) spectroscopy study showed the presence of the oxygen free radicals in similar reaction conditions. ${ }^{43}$ On the other hand, the strongly reduced $\mathrm{CO}_{2}$ formation at almost constant $\mathrm{NO}_{x}$ conversion during the second run, confirms the gradual oxidation of graphitic $\mathrm{CB}$ (Table 1). 
(a)
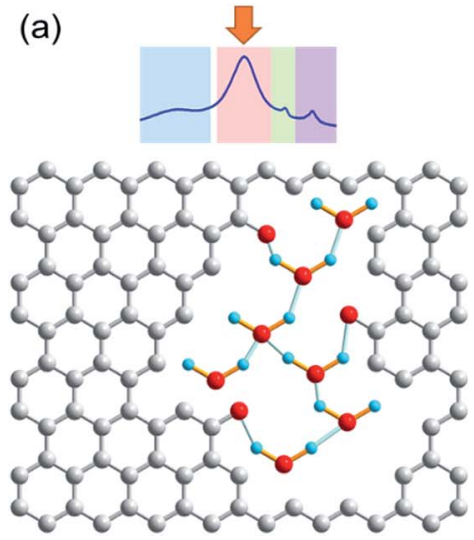

(b)
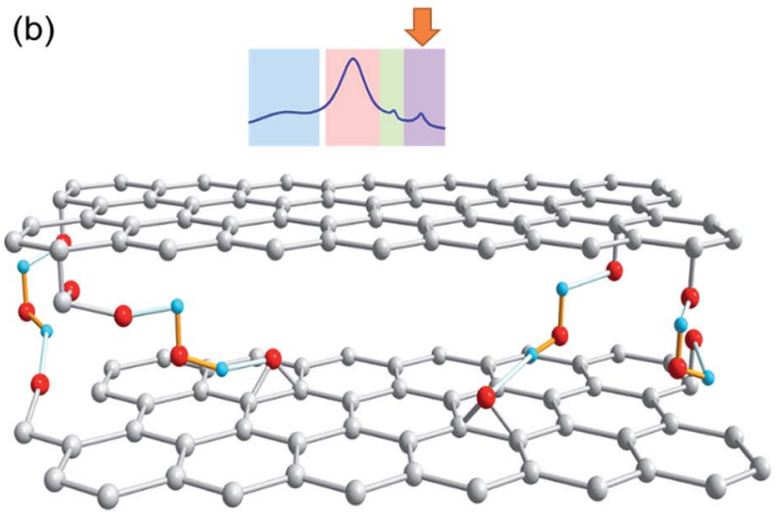

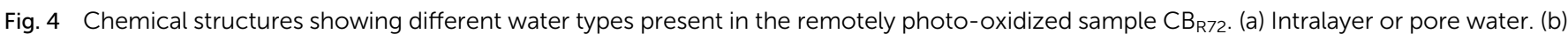
Interlayer water.

Further structural changes such as crystallinity and interlayer distance are resolved from X-ray diffraction, as shown in Fig. 6. In the diffraction patterns, two reflections can be observed at respectively, 24.1 and 43.1 degrees $2 \theta$. The most intense reflection (at. $24.1^{\circ} 2 \theta$ ) arises from X-rays diffracted by the (002) graphitic planes in the CB..$^{3,44-46}$ The second corresponds to the $(100) /(101)$ reflections of the graphitic fraction of $\mathrm{CB}$. Upon remote photo-oxidation the

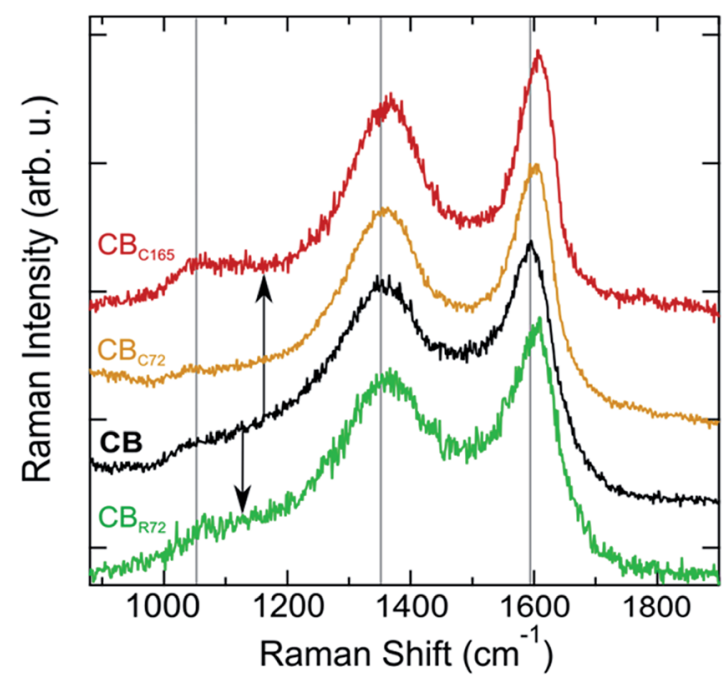

Fig. 5 Comparison of Raman spectra of pristine $C B, \mathrm{CB}_{\mathrm{C} 72}, \mathrm{CB}_{\mathrm{C} 165}$ and $\mathrm{CB}_{\mathrm{R} 72}$.
(002) diffraction peak becomes sharper, confirming the removal of amorphous carbon and gradually increasing contribution of graphitic carbon. Additionally, the (002) peak shifts towards higher angles, implying a reduction in interplanar distance $\left(d_{002}\right)$. Note that this inter-plane spacing in pure graphite is $3.35 \AA$ as compared to 3.5 to $3.7 \AA$ in the present samples. ${ }^{47}$ Selective mineralization of the amorphous carbon causes the transition of the turbostratic graphitic-like crystallite structure into more perfectly ordered ABA stacking of graphite layers. A similar decrease in $d_{002}$ spacing was also observed by Asokan et al., upon treating CB with microwave irradiation. ${ }^{44}$

SEM analysis (Fig. 7) reveals the morphology of pristine and oxidized CB by both contact and remote photocatalysis. Photo-oxidized CB particles have become smaller and are less spherical in shape. $\mathrm{CB}_{\mathrm{C} 72}$ (Fig. 7e and f) consists of smaller, elongated, carbon structures relative to $\mathrm{CB}_{\mathrm{R} 72}$ shown in Fig. $7 \mathrm{c}$ and d. Contact photocatalysis has the most dramatic effect on the nanoparticles size and shape, due to the higher photooxidation rate. The larger void spaces in $\mathrm{CB}_{\mathrm{C} 72}$ and $\mathrm{CB}_{\mathrm{R} 72}$, highlighted at lower magnifications (Fig. 7e and c), also illustrate the conversion of solid carbon fractions into gaseous $\mathrm{CO}_{x}$ by the selective carbon mineralization. The observed effect on the outer appearance of $\mathrm{CB}$ is however rather subtle since many spherical particles are still intact. Apart from the uniform particle size reductions and slight particle deformations, CB photo-oxidation mainly affects the internal chemical structure as observed by NMR, Raman and XRD analyses.

Table 2 Raman parameter results after fitting the spectra for $C B, C_{C 72}, C_{C 165}$ and $C_{B} B_{R 72}$ samples

\begin{tabular}{|c|c|c|c|c|c|c|}
\hline $\mathrm{CB}$ & 1357 (3) & $1598(2)$ & $254(9)$ & $113(5)$ & $2.9(0.3)$ & $-62(6)$ \\
\hline $\mathrm{CB}_{\mathrm{C} 165}$ & $1362(2)$ & 1606 (1) & $178(6)$ & $81(3)$ & $2.7(0.1)$ & $-43(1)$ \\
\hline $\mathrm{CB}_{\mathrm{R} 72}$ & $1359(2)$ & $1601(2)$ & 237 (11) & $109(3)$ & $2.8(0.3)$ & $-56(3)$ \\
\hline
\end{tabular}




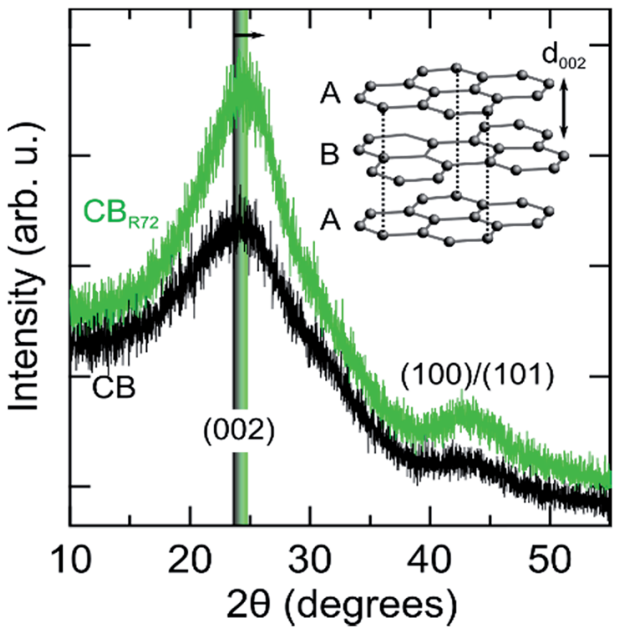

Fig. 6 XRD patterns of pristine (CB) and remotely photo-oxidized $\left(C B_{R 72}\right)$ carbon black. The inset shows the graphene sheet-like stacking giving rise to the (002) Bragg diffraction peak, which is shifted to higher scattering angles (smaller inter-plane spacing) following photo-oxidation (arrow).

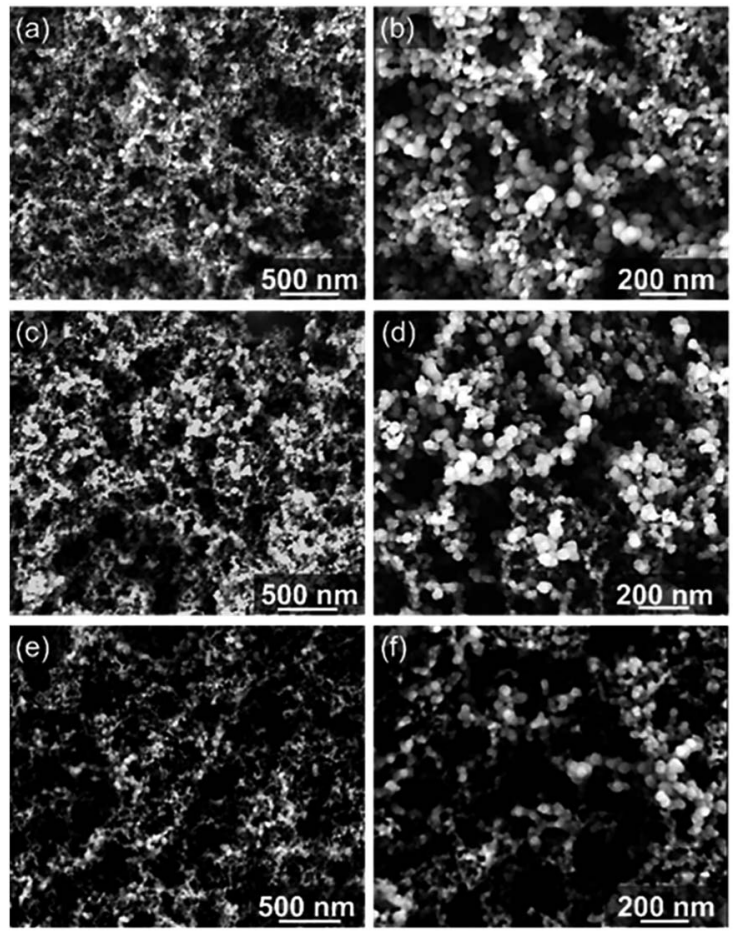

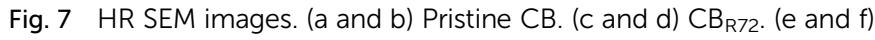
$\mathrm{CB}_{\mathrm{C} 72}$. Both contact and remote experiments were performed simultaneously in the same reactor at $150{ }^{\circ} \mathrm{C}$ for $72 \mathrm{~h}$ with gas mixture 1.

As seen in Table 3, nitrogen physisorption indicates a $\mathrm{CB}$ porosity change resulting from the gas-assisted photooxidation, as suggested by ${ }^{1} \mathrm{H}$ NMR and SEM. A large increase in BET specific surface area from $146 \mathrm{~m}^{2} \mathrm{~g}^{-1}$ to $277 \mathrm{~m}^{2} \mathrm{~g}^{-1}$ is measured after the remote photo-oxidation in gas mixture 1 at $150{ }^{\circ} \mathrm{C}$. This porosity increase is partly caused by a larger
Table 3 Specific surface area and porosity determined by $\mathrm{N}_{2}$ physisorption

\begin{tabular}{llll}
\hline Sample & $\begin{array}{l}\text { Surface area } \\
{\left[\mathrm{m}^{2} \mathrm{~g}^{-1}\right]}\end{array}$ & $\begin{array}{l}\text { Pore volume } \\
{\left[\mathrm{cm}^{3} \mathrm{~g}^{-1}\right]}\end{array}$ & $\begin{array}{l}\text { Micropore volume } \\
{\left[\mathrm{mL} \mathrm{g}^{-1}\right]}\end{array}$ \\
\hline $\mathrm{CB}$ & $146 \pm 2$ & 0.157 & 0.043 \\
$\mathrm{CB}_{\mathrm{R} 72}$ & $277 \pm 5$ & 0.221 & 0.102
\end{tabular}

number of micropores. Selectively removing the amorphous carbon from otherwise graphitic CB nanoparticles leads to a larger microporous volume, covering almost completely the increase in cumulative pore volume. These microporous volumes are determined using $t$-plot nitrogen adsorption isotherms (Harkins and Jura), shown in the ESI (Fig. S4†). Additionally, the increase in specific surface area is assumed to be due to the decreasing particle size and larger gaps between the particles upon photo-oxidation, indicated by SEM. ${ }^{\mathbf{1 , 4 8}}$ The CB surface area is nearly doubled due to the remote photocatalytic treatment, which causes many small pores and interparticle gaps. Therefore, graphitic CB fractions become more accessible by the removal of conjunctive amorphous carbon and increase of total void fraction, shown in Fig. 7. Note that a porous CB with relatively higher graphitic carbon content is of great scientific interest for adsorbent applications. Strong evidence for the oxygen functionalization of the graphitic carbon is further provided.

The structural and chemical analysis of the different CBs is summarized in Fig. 8 by means of TEM, EELS and EDS. In the HR TEM images, graphitic carbon structures with curved and facetted sections can be seen in all samples with interplanar spacing strongly varying between $0.3 \mathrm{~nm}$ and $0.43 \mathrm{~nm}$. EELS spectra confirm the $\mathrm{sp}^{2}$-type graphitic structure with the presence of the characteristic peaks at $285 \mathrm{eV}$ and $290 \mathrm{eV}$ corresponding to transitions to the $\pi^{*}$ and $\sigma^{*}$ orbitals (Fig. 8a). The sharp $\pi^{*}$ peak at $285 \mathrm{eV}$, which is characteristic of $\mathrm{sp}^{2}$-hybridized carbon, is the highest for the CB-contact sample and the lowest for the CB-reference, confirming the increased graphitization degree after photocatalytic oxidation. However, it has to be noted that the EELS were taken not from one specific carbon particle but from a larger area in order to limit the irradiation damage. Therefore, the Ti- and $\mathrm{O}$ absorption edges are also visible in the CB-contact sample. Carbon materials are well known to be strongly sensitive to electron irradiation, in particular, at a high acceleration voltage due to the knock-on displacement of carbon atoms. ${ }^{49,50}$ Therefore, a quantitative comparison of the carbon structure is difficult.

Upon contact and remote photocatalytic treatment, samples exhibit oxygen signals at $532 \mathrm{eV}$ (see inset of Fig. 8a), which are absent in the CB-reference sample, demonstrating the photooxidation effectiveness. In the CB-contact sample, the oxidation also becomes visible in the EDS chemical map (Fig. 8b): at the location of carbon nanoparticles (red in the filtered C-map) a trace of oxygen can be seen whereas Ti-is absent. The line-scan across the carbon nanoparticles indeed confirms the presence of oxygen due to effective oxidation. 


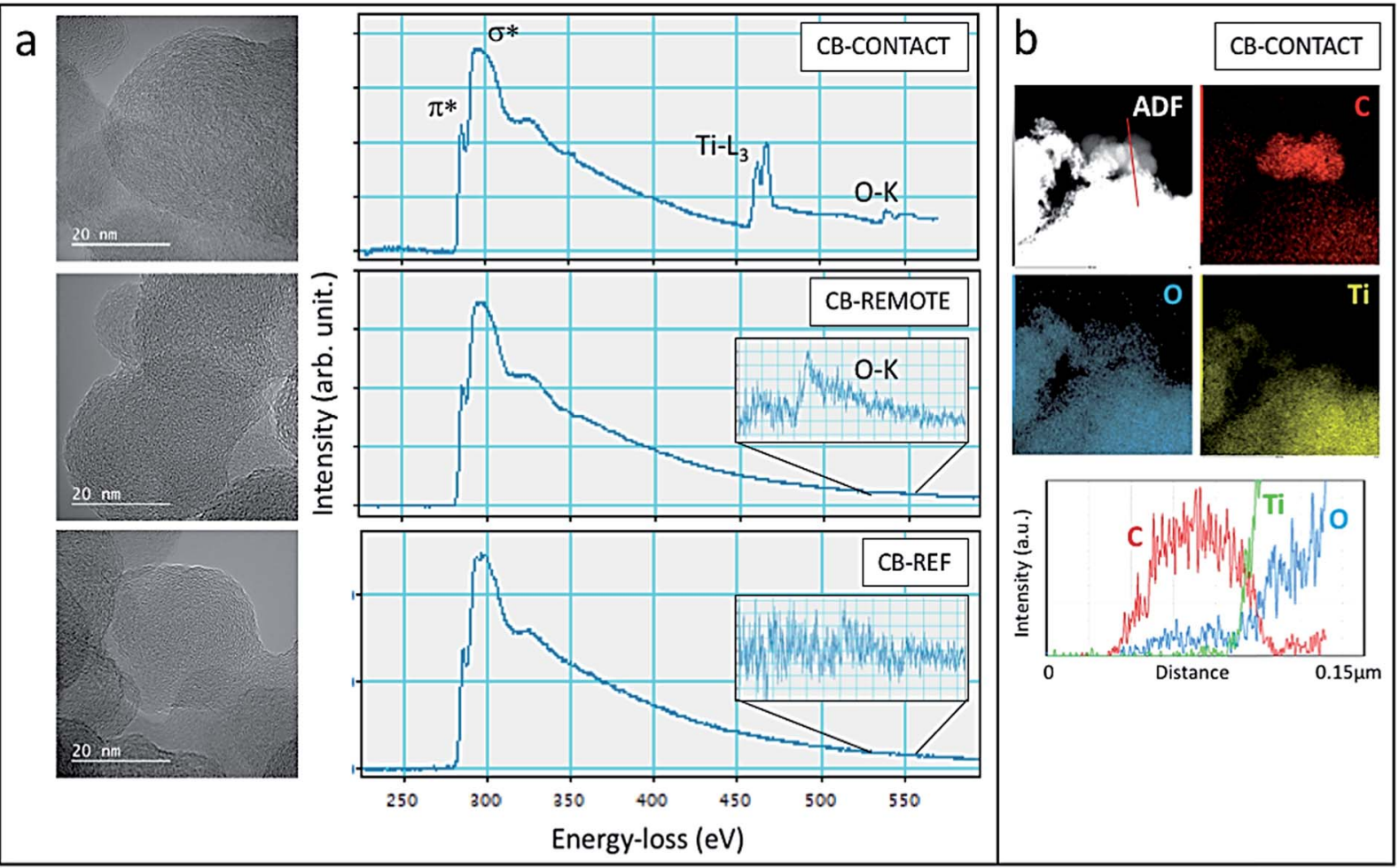

Fig. 8 (a) HR TEM images and EELS spectra of CB-contact (top), CB-remote (middle) and CB-reference (bottom). The insets show magnified EELS spectra of the O-K peak. (b) The STEM-ADF image of the CB-contact sample with the respective EDS maps for $C-K, O-K$ and Ti-K and the line-scan (bottom) across the red line indicates the presence of oxygen in $C B$.

\section{Conclusions}

The amorphous carbon fraction present in carbon black is selectively mineralized using oxidative $\mathrm{TiO}_{2}$ photocatalysis in $\mathrm{O}_{2}$, $\mathrm{NO}_{x}$ and $\mathrm{H}_{2} \mathrm{O}$. Photocatalytic $\mathrm{CB}$ oxidation is performed by either physical contact or by remote photocatalyst control. In contrast to CB pyrolysis, the carbon is chemically modified at low temperature through this photocatalytic treatment. Easily oxidizable and refractory carbon fractions of $\mathrm{CB}$ react differently via the gasassisted photocatalytic oxidation. A partially graphitized CB with high water affinity is obtained by preferentially removing the disordered $\mathrm{sp}^{3}$-hybridized carbon over the graphitic $\mathrm{sp}^{2}$-hybridized carbon fraction. The graphitic carbon product is activated by strongly increased porosity and oxygen functionalization due to the selective oxidation process. Photo-oxidation causes furthermore a size reduction of the elementary CB particles, and a shape change from spherical to slightly elongated. Photo-oxidation with anatase $\mathrm{TiO}_{2}$ offers an eco-friendly way of selectively removing the amorphous CB fraction, while functionalizing the graphitic carbon. The final porous CB enriched with oxidized graphitic carbon fractions could potentially serve as adsorbent material or be used in catalyst applications. From a materials perspective, remote photo-oxidation offers an easy and powerful avenue toward the production of activated CB.

\section{Conflicts of interest}

There are no conflicts to declare.

\section{Acknowledgements}

This work was supported by long-term structural funding by the Flemish government (Methusalem). The TEM equipment was funded by the Hercules project AKUL/13/19.

\section{References}

1 M. Gautier, V. Rohani and L. Fulcheri, Int. J. Hydrogen Energy, 2017, 42, 28140-28156.

2 J.-C. Huang, Adv. Polym. Technol., 2002, 21, 299-313.

3 T. Ungár, J. Gubicza, G. Ribárik, C. Pantea and T. W. Zerda, Carbon, 2002, 40, 929-937.

4 P. Xue, J. Gao, Y. Bao, J. Wang, Q. Li and C. Wu, Carbon, 2011, 49, 3346-3355.

5 M. Pawlyta, J.-N. Rouzaud and S. Duber, Carbon, 2015, 84, 479-490.

6 J. B. Donnet, J. Schultz and A. Eckhardt, Carbon, 1968, 6, 781788.

7 J. B. Donnet, Carbon, 1994, 32, 1305-1310.

8 P. A. Hartley, G. D. Parfitt and L. B. Pollack, Powder Technol., 1985, 42, 35-46.

9 A. V. Kiselev and Y. I. Yashin, Gas-Adsorption Chromatography, Plenum Press, 1969.

10 F. Bruner, G. Crescentini and F. Mangani, Chromatographia, 1990, 30, 565-572.

11 K. R. Kim, Y. J. Lee, H. S. Lee and A. Zlatkis, J. Chromatogr., 1987, 400, 285-291. 
12 E. Charon, J.-N. Rouzaud and J. Aléon, Carbon, 2014, 66, 178190.

13 T. Gruber, T. W. Zerda and M. Gerspacher, Carbon, 1994, 32, 1377-1382.

14 T. W. Zerda and T. Gruber, Rubber Chem. Technol., 2000, 73, 284-292.

15 H. Marsh and A. P. Warburton, J. Chem. Technol. Biotechnol., 1970, 20, 133-142.

16 I. Mochida, R. Ohtsubo and K. Takeshita, Carbon, 1980, 18, 117-123.

17 I. Mochida, I. Ito, Y. Korai, H. Fujitsu and K. Takeshita, Carbon, 1981, 19, 457-465.

18 T. W. Zerda, W. Xu, A. Zerda, Y. Zhao and R. B. Von Dreele, Carbon, 2000, 38, 355-361.

19 L.-W. Zhang, H.-B. Fu and Y.-F. Zhu, Adv. Funct. Mater., 2008, 18, 2180-2189.

20 K. Lv, S. Fang, L. Si, Y. Xia, W. Ho and M. Li, Appl. Surf. Sci., 2017, 391, 218-227.

21 L. Liao, S. Heylen, B. Vallaey, M. Keulemans, S. Lenearts, M. B. J. Roeffaers and J. A. Martens, Appl. Catal., B, 2015, 166-167, 374-380.

22 L. Liao, S. Heylen, S. P. Sree, B. Vallaey, M. Keulemans, S. Lenaerts, M. B. J. Roeffaers and J. A. Martens, Appl. Catal., B, 2017, 202, 381-387.

23 B. H. R. Suryanto and C. Zhao, Chem. Commun., 2016, 52, 6439-6442.

24 T. Tatsuma, S. Tachibana, T. Miwa, D. A. Tryk and A. Fujishima, J. Phys. Chem. B, 1999, 103, 8033-8035.

25 T. Tatsuma, S. Tachibana and A. Fujishima, J. Phys. Chem. B, 2001, 105, 6987-6992.

26 A. Mills, S. Hodgen and S. K. Lee, Res. Chem. Intermed., 2005, 31, 295-308.

27 U. I. Gaya and A. H. Abdullah, J. Photochem. Photobiol., C, 2008, 9, 1-12.

28 S. W. Verbruggen, K. Masschaele, E. Moortgat, T. E. Korany, B. Hauchecorne, J. A. Martens and S. Lenearts, Catal.: Sci. Technol., 2012, 2, 2311-2318.

29 A. Fujishima, X. Zhang and D. A. Tryk, Surf. Sci. Rep., 2008, 63, 515-582.
30 J.-M. Herrmann, Catal. Today, 1999, 53, 115-129.

31 C. J. Tighe, M. V. Twigg, A. N. Hayhurst and J. S. Dennis, Carbon, 2016, 107, 20-35.

32 N. Nejar, M. Makkee and M. J. Illán-Gómez, Appl. Catal., B, 2007, 75, 11-16.

33 Z. Meng, D. Yang and Y. Yan, J. Therm. Anal. Calorim., 2014, 118, 551-559.

34 A. M. Panich, V. Y. Osipov and K. Takai, New Carbon Mater., 2014, 29, 392-397.

35 M. Concistrè, S. Mamone, M. Denning, G. Pileio, X. Lei, Y. Li, M. Carravetta, N. J. Turro and M. H. Levitt, Philos. Trans. $R$. Soc., A, 2013, 371, 1-11.

36 F. Tuinstra and J. Koenig, J. Chem. Phys., 1970, 53, 11261130.

37 R. J. Nemanich, G. Lucovsky and S. A. Solin, Solid State Commun., 1977, 23, 117-120.

38 R. J. Nemanich and S. A. Solin, Phys. Rev. B: Solid State, 1979, 20, 392-401.

39 T. Jawhari, A. Roid and J. Casado, Carbon, 1995, 33, 15611565.

40 A. N. Mohan, B. Manoj and A. V. Ramya, Asian J. Chem., 2016, 28, 1501-1504.

41 A. C. Ferrari and J. Robertson, Phys. Rev. B: Condens. Matter Mater. Phys., 2000, 61, 14095-14107.

42 J. Robertson, Adv. Phys., 2011, 60, 87-144.

43 M. Smits, Y. Ling, S. Lenaerts and S. Van Doorslaer, ChemPhysChem, 2012, 13, 4251-4257.

44 V. Asokan, V. Venkatachalapathy, K. Rajavel and D. N. Madsen, J. Phys. Chem. Solids, 2016, 99, 173-181.

45 M. S. Seehra and A. S. Pavlovic, Carbon, 1993, 31, 557-564.

46 V. S. Babu, L. Farinash and M. S. Seehra, J. Mater. Res., 1995, 10, 1075-1078.

47 P. J. F. Harris, Interdiscip. Sci. Rev., 2001, 26, 204-210.

48 L. Gao, Q. Li, Z. Song and J. Wang, Sens. Actuators, B, 2000, 71, 179-183.

49 B. W. Smith and D. E. Luzzi, J. Appl. Phys., 2001, 90, 35093515.

50 R. F. Egerton, Microsc. Res. Tech., 2012, 75, 1550-1556. 